\title{
Delayed intracerebral hemorrhage after ventriculoperitoneal shunt insertion. Case report and literature review
}

L. Alcázar; R. Alfaro; M. Tamarit; J.C. Gómez-Angulo; J.M. Ortega; P. Aragonés; P. Jerez; F. Salazar y J.M. del Pozo

Department of Neurosurgery. The Getafe Universitary Hospital. Getafe. Madrid. Spain.

\section{Summary}

We present another case of delayed intracerebral hemorrhage after a ventriculoperitoneal (VP) shunting procedure. In this case, a right occipital intraparenchymal hematoma and associated intraventricular hemorrhage occurred six days after the operation for hydrocephalus secondary to subarachnoid hemorrhage in a 64 year old woman. It is a rare complication of VP shunting, with few cases reported previously in the literature. The presumed mechanism is the erosion of a cerebral blood vessel secondary to a close contact with the ventricular catheter; bleeding disorder, vascular malformation, head trauma or brain tumor were excluded in this patient.

KEY WORDS: Intracerebral hemorrhage. Ventriculoperioneal shunt. Hydrocephalus. Postoperative complication. Ventricular catheter.

Hemorragia intracerebral tardía tras la colocación de una derivación ventriculoperitoneal. Caso clínico y revisión de la literatura

\section{Resumen}

Presentamos un caso de hemorragia intracerebral tardía tras la colocación de una derivación ventriculoperitoneal. Una paciente de 64 años de edad, con hidrocefalia secundaria a una hemorragia subaracnoidea, sufre una hemorragia intraparenquimatosa occipital derecha con hemorragia intraventricular secundaria seis días después de la intervención quirúrgica. Se trata de una complicación rara de la derivación ventriculoperitoneal, con pocos casos publicados anteriormente. El mecanismo supuesto es la erosión de un vaso sanguíneo secundaria a un íntimo contacto con el catéter proximal de la derivación; trastornos sanguíneos, malformaciones vasculares cerebrales, trauma-

Recibido: 23-02-06. Aceptado: 16-05-06 tismo craneal o tumor cerebral fueron excluidos en esta paciente.

PALABRAS CLAVE: Hemorragia intracerebral. Derivación ventriculoperitoneal. Hidrocefalia. Complicación postquirúrgica. Catéter ventricular.

Introduction

Complications of cerebrospinal fluid (CSF) ventricular shunting have been reported ${ }^{19,23}$ a lot of years ago, such as infections, shunt malfunction, subdural hematomas, seizures, migrating catheter, kinked tubing. Small amounts of blood are frequently recognized in the ventricle or in the parenchyma along the catheter path $^{16}$, but clinically significant lesions, however, are uncommon ${ }^{7,15,23}$. Fukamachi explain on his report in 1985 that intracerebral hemorrhage after a ventricular shunting procedure is uncommon, usually occurring soon after surgery ${ }^{6}$. In several large series reviewing the complications of this procedure authors don't mention intracerebral hemorrhage ${ }^{17,19}$. We can find some reports of such a complication ${ }^{9,16,19,23}$ in which the hemorrhage occurred directly after the operative procedure. Bleeding secondary to ventricular puncture may be detected on imaging studies (ultrasonography, computerized tomography-CT, magnetic resonance imaging-MRI), but they are not ordered in uncomplicated cases ${ }^{22}$; therefore, the incidence of delayed intracerebral hemorrhage following ventricular cannulation is difficult to establish.

This type of complication had not been described in the literature until 1985, when Matsumura et al reported a case of delayed intracerebral hemorrhage that occurred after a ventriculoperitoneal (VP) shunting procedure in a 17 year-old boy on the $7^{\text {th }}$ postoperative day ${ }^{15}$. Posteriorly, other two cases of this surgical complication have been

Abreviations. CSF: cerebrospinal fluid. CT: computerized tomography. DIC: disseminated intravascular coagulation. GCS: Glasgow coma scale. MRI: magnetic resonance imaging. VP: ventriculoperitoneal. 


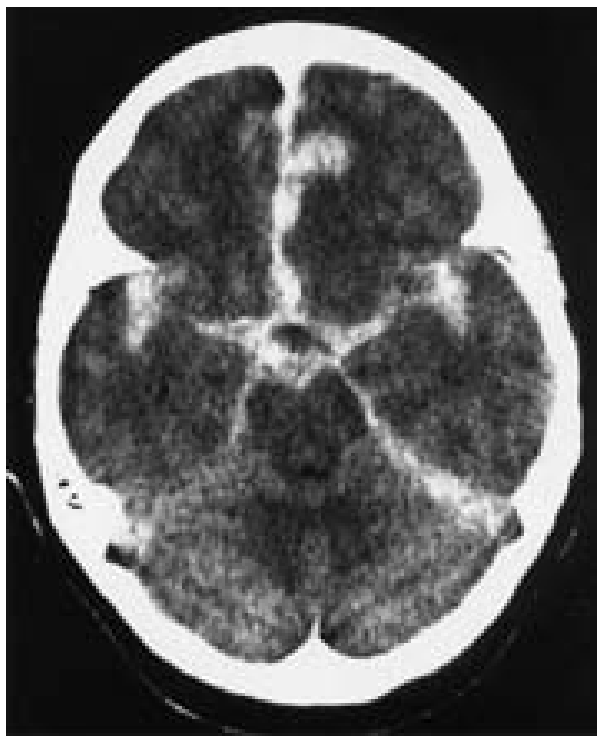

Figure 1. CT scan showing a widespread subarachnoid hemorrhage within basal cisterns, both silvian fissures and an interhemispheric hematoma.

reported ${ }^{14,22}$ and Savitz et al performed in $1999^{18}$ a retrospective analysis in a series of $125 \mathrm{VP}$ shunting procedures, documenting by routine neuroradiological follow up (CT scan obtained within 48 hours of surgery) a rate of delayed intracerebral or intraventricular hematoma of $4 \%$.

We report a case of delayed intraparenchymal hemorrhage, along the path of the ventricular catheter, which occurred six days after a VP shunting procedure and review the previous literature about this rare complication.

\section{Case report}

A 64 year-old woman was admitted to the neurosurgical department of our hospital on January 20, 2002, being diagnosed of subarachnoid hemorrhage (grade III, HuntHess scale). She was brought because of transient loss of conciousness for several minutes following a sudden headache in the morning. The past history was unremarkable. The neurological examination on admission showed right hemiparesis with a punctuation in the Glasgow Coma Scale (GCS) of 13/15. A computed tomographic (CT) scan demonstrated a widespread subarachnoid hemorrhage, an interhemispheric hematoma and a small acute left temporal subdural hematoma (Figure 1).

The conventional cerebral angiography was not completed because of the appereance of left hemiparesis; so a $\mathrm{CT}$ angiogram was performed revealing a right pericallosal artery aneurysm (Figure 2) which was supposed to be the cause of the bleeding.

The patient was not operated on immediately because her clinical evolution was not favourable. The surgical pro-

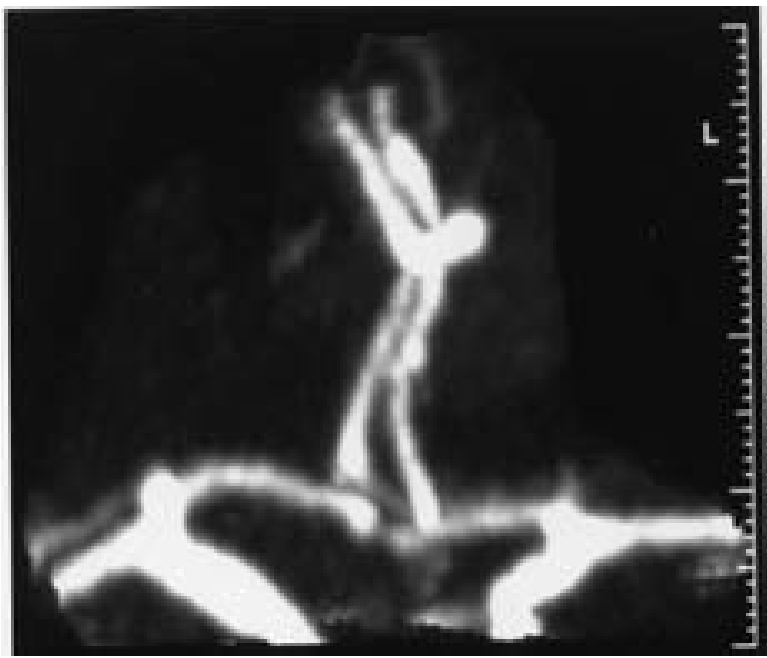

Figure 2. The CT angiogram revealed a right pericallosal artery aneurysm $(2.7 \times 5.2 \mathrm{~mm})$ as CT scan on admission suggested.

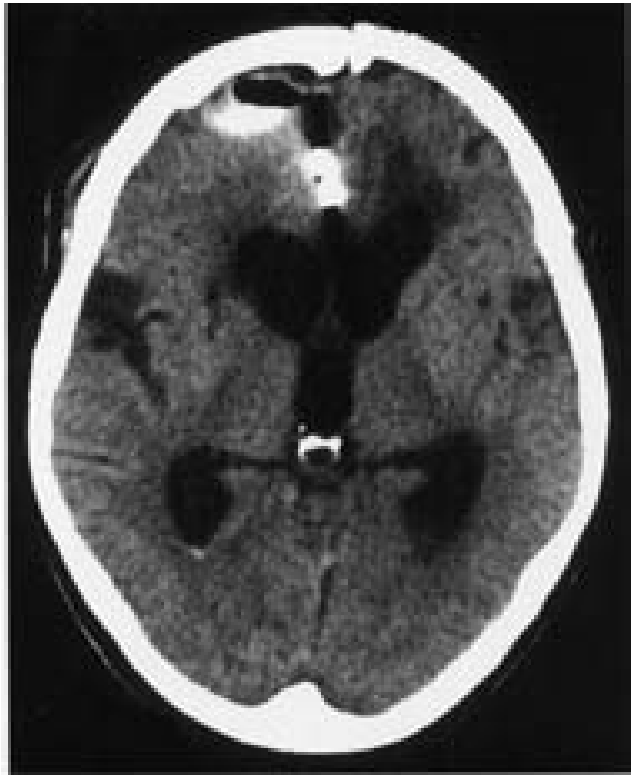

Figure 3. CT scan performed fifteen days after the clipping of the aneurysm. It can be observed postsurgical changes related to the right frontal craniotomy and marked ventricular dilatation.

cedure was performed one month later, when her clinical situation improved (GCS 13/15); the described aneurysm was clipped through a right frontal parasagital craniotomy, without intraoperative complications.

She initially did quite well, although very slowly. A CT scan performed 15 days after the operation revealed marked ventricular dilatation compared with previous imaging study performed on admission (Figure 3). By this, a VP shunt was placed in the patient on March 11; through a right occipital burr hole a ventricular catheter was inserted in 

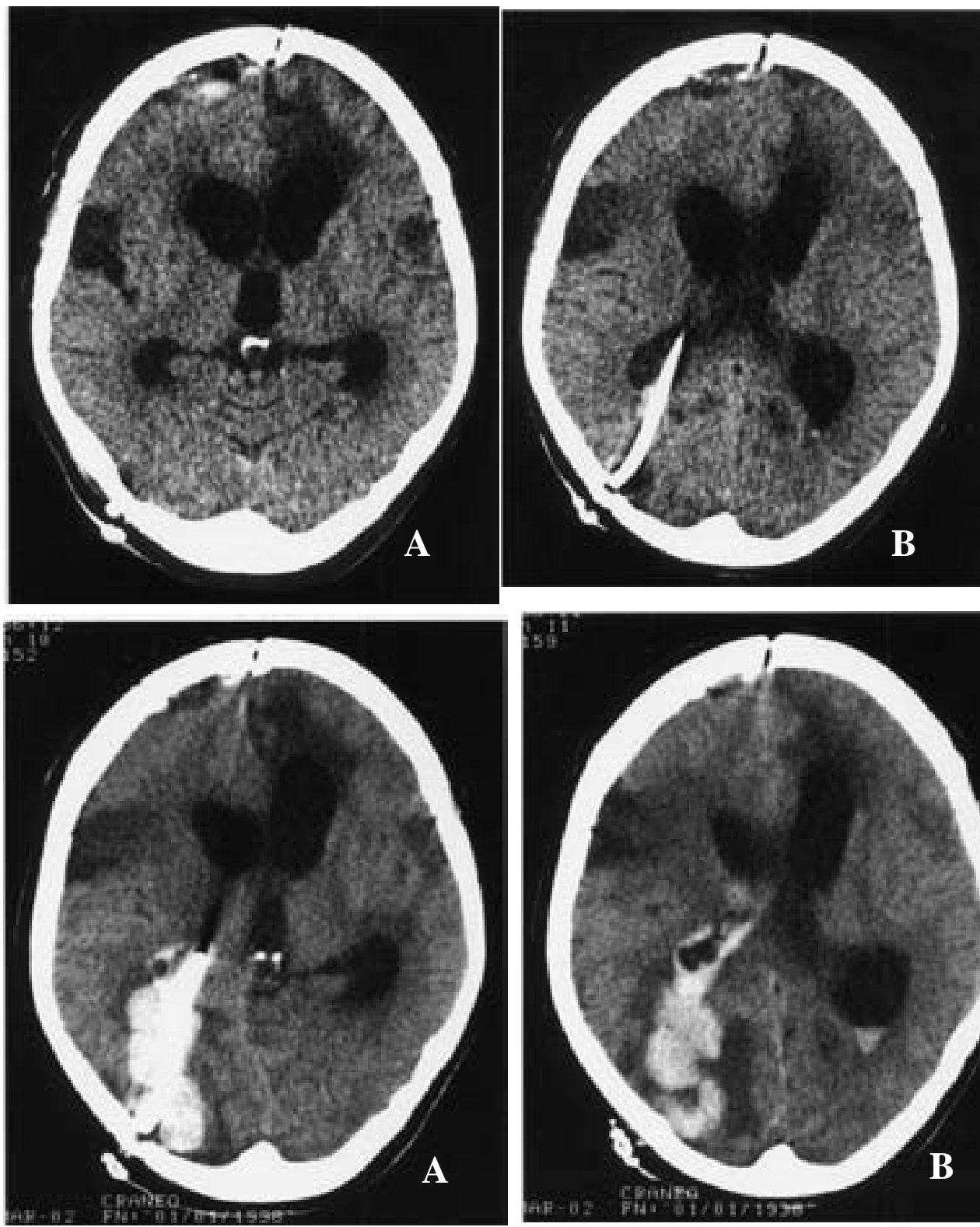

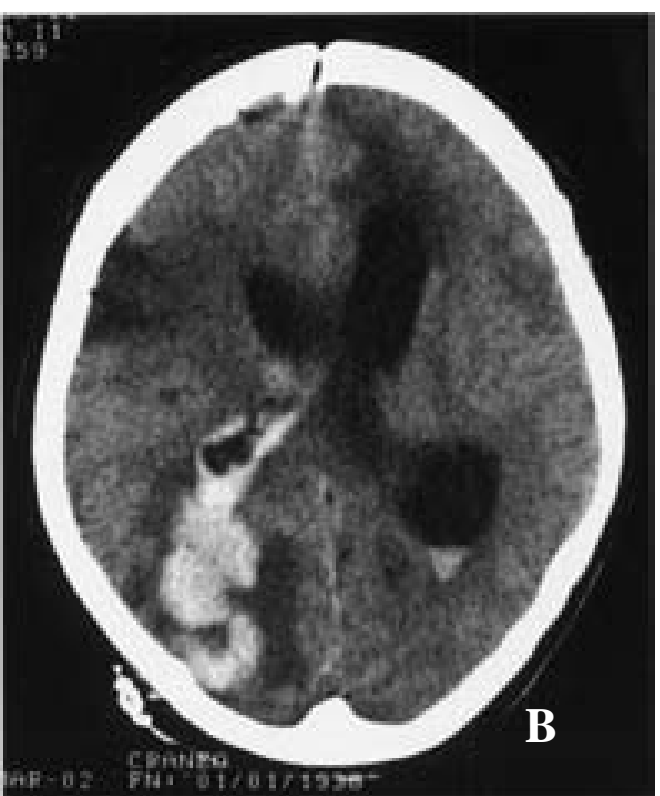

Figure 4. (A, B). Postoperative $C T$ scan performed 24 hours following ventriculoperitoneal shunt insertion that showed no decreased ventricular size compared with the previous imaging study.
Figure 5. $(A, B)$. The third postoperative $C T$ scan performed five days after the ventriculoperitoneal shunt insertion revealed a right occipital intraparenchymal hemorrhage along the path of the ventricular catheter and into the ventricular system; ventricular size remained without changes. the right lateral ventricle, connected to a Hakim programmable valve (pressure $100 \mathrm{mmH}_{2} \mathrm{O}$ ). The operative procedure was uneventful; correct placement of the ventricular catheter was accomplished after one pass. Because of the absence of improvement and no decreased ventricular size (CT scan performed after 24 hours) (Figure 4), the valve was reprogrammed, this time at $80 \mathrm{mmH}_{2} \mathrm{O}$; after it, the patient improved in attention and verbal response.

She deteriorated five days later becoming less alert, without collaboration. This time the patient didn't well; 24 hours later she remained with closed eyes, absence of verbal response and localizing to painful stimulus. The new CT scan (Figure 5) revealed a right occipital intraparenchymal hematoma, around the ventricular catheter, with opening to the ventricular system and ventricular size without changes. She was operated on for revision of the VP shunt that proved to be obstructed; it was removed and we inserted an external ventricular drainage through a right frontal burr hole. The system of drainage obstructed repeatedly and the ventricular catheter was inserted in the left frontal horn and in the right temporal horn of the lateral ventricles subsequently.

The clinical course was unfavourable and the patient was again operated on for evacuation of the intraparenchymal and intraventricular hemorrhage through a right occipital craniotomy. The subsequent improvement was slight; she remained conscious, with open eyes, but without verbal response and submission. The CT scan performed after this 
operative procedure demonstrated minimal intraparenchymal hematoma in the right occipital lobe, with less edema and minimal shift of the medium line.

The patient deteriorated progressively, with renal failure and fever toward the multiorganic failure that caused the death of the patient on May 25, 2002.

\section{Discussion}

Ventriculoperitoneal shunting (VP) is one of the most frequently performed procedure in our daily neurosurgical practice. All of us know complications following insertion of a CSF shunt, such as infection, obstruction, subdural hematoma, malfunction, seizures, migrating or kinked catheter ${ }^{19,23}$; obstruction or blockage of the ventricular and abdominal ends of the tubing and infection of the system are the major problems of CSF shunting procedures. Postoperative intracerebral or intraventricular hematoma usually ocurr soon after ventricular puncture ${ }^{6}$. In the pediatric population intracranial hemorrhage may be seen after $0.4 \%$ to $4 \%$ of shunt operations ${ }^{9,15,16}$.

Several mechanisms whereby intracerebral hemorrhage can ocurr after ventricular cannulation can be described $^{22}$ : coexistant bleeding disorder, shunt-induced disseminated intravascular coagulation, disruption of an intracerebral vessel by the catheter, hemorrhage into an intracerebral tumor, hemorrhage from an occult vascular malformation and head trauma occurring shortly after shunt placement. Disseminated intravascular coagulation (DIC) has been reported after head trauma ${ }^{8,13}$, brain tumor surgery ${ }^{6}$ and VP shunting ${ }^{20}$. On the other hand, intratumoral hemorrhage has been described following ventricular cannulation ${ }^{24,25,27}$.

Bleeding along the path of the ventricular catheter and into the ventricular system has been reported previously following VP shunt placement ${ }^{2,6,10,14,19,23}$; it may be caused by puncture of the choroid plexus, repeated attempts at perforation of the ventricles or inadequate placement of the tubing within the parenchyma of the brain.

Savitz et al reported in 1999 a series of 125 adults operated on for primary insertion of a one-piece shunting system ${ }^{18}$; each one was evaluated based on a CT scan obtained within 48 hours of surgery; no bleeding was observed in the CSF at the time of the ventricular cannulation; they recorded three cases of postoperative intraventricular hemorrhage and delayed hemorrhage around the catheter in the right parietal area was documented on postoperative CT scan in two patients. The mechanism in these five patients was more likely disruption of a cerebral blood vessel by the catheter; the normal pulsations of the CSF transmitted to the tubing might have caused the catheter to erode through a blood vessel with subsequent intracerebral hemorrhage.
Snow et al proposed a similar mechanism on his report in $1986^{22}$ about a delayed intracerebral hemorrhage in a 43 year-old woman seven days after a VP shunting procedure. Matsumura et $\mathrm{al}^{15}$ described the case of a 17 yearold boy who developed a marked ventricular dilatation two years after an operation for a traumatic intracerebral hematoma. Fujioka ${ }^{5}$ presented to us another case of intracerebral hematoma after a ventricular puncture in the same location; he hypothesized that the bleeding might have occurred by the same mechanism as traumatic delayed intracerebral hemorrhage ${ }^{1,4,21}$. Mascalchi ${ }^{14}$ presented in 1991 the case of a patient with an extensive intraparenchymal hemorrhage far from the catheter of the VP shunt ${ }^{12,14}$.

CT scans are not often obtained within the first week after an uneventful ventricular shunting procedure, so the true incidence of intracerebral hemorrhage after it is difficult to know. The CT scan finding of small amounts of blood within the ventricle occurred in $10 \%$ of the cases in the Palmieri's series; less frequently small pools of blood were noted under the ependyma next to the catheter tip or along its path in the parenchyma. Savitz in 1999 determined with his analysis an incidence of delayed intracerebral hemorrhage of $4 \%{ }^{18}$. Snow ${ }^{22}$ reported an incidence of moderate hemorrhage after ventricular shunting procedures of $0.3 \%$ ( 3 to $5 \mathrm{~cm}$ in maximal diameter). Fukamachi et al performed CT scans on 242 patients within the first week of ventricular shunting procedures ${ }^{6}$ and found that ten of them had small intracerebral hematomas ( $3 \mathrm{~cm}$ maximal diameter); they didn't offer any explanation for the one moderate-sized hematoma in their series. Udvarhelyi et $\mathrm{al}^{23}$ reported two cases of intracerebral hematoma after VP shunting among 55 cases of normal pressure hydrocephalus. Sayers ${ }^{19}$ reported six cases of intracerebral hematoma among 1390 shunted cases. The incidence in these reports varies from $0.4 \%^{3}$ to $3.6 \%{ }^{23}$. In spite of the low incidence of this complication, mortality is high, ranging from $50 \%{ }^{19}$ to $100 \%$.

The cause of the right occipital intraparenchymal hemorrhage in our patient remains unknown; the mechanism could have been the erosion of a surface or deeper cerebral blood vessel secondary to a close contact between the tubing and the blood vessel, as the cases described by Savitz ${ }^{18}$ and $S^{2}{ }^{22}$. We can think in favour of this mechanism because no hemorrhagic CSF was observed following puncture of the lateral ventricle and the first CT scan performed after the shunting procedure didn't demonstrate any intracerebral hemorrhage. Bleeding disorder, tumor, occult vascular malformation or head trauma were not the cause of this event as clinical examination, laboratory tests and radiological studies determined. Another possible factor we think could have 
influence it is the handling of the valve system; the patient deteriorated five days after changing its opening pressure (from $100 \mathrm{mmH}_{2} \mathrm{O}$ to $80 \mathrm{mmH}_{2} \mathrm{O}$ ); nevertheless, the ventricular size didn't reduce following the manipulation of the valve, as the CT scan performed at the moment of the deterioration demonstrated.

Here we report another case of this unusual complication, review the previous literature about cerebral hemorrhagic complications after ventricular shunting procedures and discuss the supposed causative factors and mechanisms involved in this infrequent event.

\section{References}

1. Baratham, G., Dennyson, W.G.: Delayed traumatic intracerebral hemorrhage. Journal of Neurology, Neurosurgery and Psychiatry 1972; 35: 698-706.

2. Derdeyn, C.P., Delashaw, J.B., Broaddus, W.C., Jane, J.A.: Detection of shunt-induced intracerebral hemorrhage by postoperative skull films: a report of two cases. Neurosurgery 1988; 22: 755-757.

3. Choux, M., Genitori, L., Lang, D., Lena, G. : Shunt implantation reducing the incidence of shunt infection. Journal of Neurosurgery 1992; 77: 875-880.

4. Evans, J.P., Scheinker, M.: Histologic studies of the brain following head trauma. II. Post-traumatic petechial and massive intracerebral hemorrhage. Journal of Neurosurgery 1946; 3: 101-113.

5. Fujioka, S., Matsumado, Y., Kaku, M., Yano, T., Yoshioka, S.: Delayed apoplexy following ventricular puncture. A case report. Neurological Surgery 1982; 10: 955-958.

6. Fukamachi, A., Koizumi, H., Nukui, H.: Postoperative intracerebral hemorrhages: a survey of computed tomographic findings after 1074 intracranial operations. Surgical Neurology 1985; 23: 575-580.

7. Ivan, L.P., Choo, S.H., Ventureyra, E.C.G.: Complications of ventriculoatrial and ventriculoperitoneal shunts in a New Children's Hospital. The Canadian Journal of Surgery 1980; 23: 566-568.

8. Keimowitz, R.M., Annis, B.L.: Disseminated intravascular coagulation associated with massive brain injury. Journal of Neurosurgery 1973; 39: 178-180.

9. Kuwamura, K., Kokunai, T.: Intraventricular hematoma secondary to a ventriculoperitoneal shunt. Neurosurgery 1982; 10: 384-386.

10. Lund-Johansen, M., Svendsen, F., Wester, K.: Shunt failures and complications in adults as related to shunt type, diagnosis and the experience of the surgeon. Neurosurgery 1994; 35: 839-844.

11. Mahony, B.S., Gross, B.H., Callen, P.W., Filly, R.A., Edwards, M.S.B.: Intraventricular hemorrhage following ventriculoperitoneal shunt placement: real-time ultrasonogra- phic demonstration. Journal of Ultrasound in Medicine 1983; 2: 143-145.

12. McCullough, D.C., Fox, J.L.: Negative intracranial pressure hydrocephalus in adults with shunts and its relationship to the production of subdural hematoma. Journal of Neurosurgery 1974; 40 . 372-375.

13. McGaulley, J.L., Miller, C.A., Penner, J.A.: Diagnosis and treatment of diffuse intravascular coagulation following cerebral trauma. Journal of Neurosurgery 1975; 43: 374-376.

14. Mascalchi, M.: Delayed intracerebral hemorrhage after CSF shunt for communicating "normal-pressure" hydrocephalus. Case report. Italian Journal of Neurological Sciences 1991; 12: 109-112.

15. Matsumura, A., Shinohara, A., Munekata, K., Maki, Y.: Delayed intracerebral hemorrhage after ventriculoperitoneal shunt. Surgical Neurology 1985; 24: 503-506.

16. Palmieri, A., Pasquini, U., Menichelli, F., Salvolini, U.: Cerebral damage following ventricular shunt for infantile hydrocephalus evaluated by computed tomography. Neuroradiology 1981; 21: 33-35.

17. Raimondi, A., Robinson, J.S., Kuwamura, K.: Complications of ventriculoperitoneal shunting and a critical comparison of the three-piece and one-piece systems. Child's Brain 1977; 3: 321-342.

18. Savitz, M., Bobroff, L.M.: Low incidence of delayed intracerebral hemorrhage secondary to ventriculoperitoneal shunt insertion. Journal of Neurosurgery 1999; 91: 32-34.

19. Sayers, M.P.: Shunt complications. Clinical Neurosurgery 1976; 23: 393-400.

20. Shurin, S., Rekate, H.: Disseminated intravascular coagulation as a complication of ventricular catheter placement. Case report. Journal of Neurosurgery 1981; 54: 264267.

21. Smith, D.R., Ducker, T.B., Kempe, L.G.: Experimental in vivo microcirculatory dynamics in brain trauma. Journal of Neurosurgery 1969; 30: 664-672.

22. Snow, R.B., Zimmerman, R.D., Devinsky, O.: Delayed intracerebral hemorrhage after ventriculoperitoneal shunting. Neurosurgery 1986; 19: 305-307.

23. Udvarhelyi, G.B., Wood, J.H., James, A.E., Bartelt, D.: Results and complications in 55 patients with normal pressure hydrocephalus. Surgical Neurology 1975; 3: 271275.

24. Vaquero, J., Cabezudo, J.M., García de Sola, R., Nombela, L.: Intratumoral hemorrhage in posterior fossa tumors after ventricular drainage. Report of two cases. Journal of Neurosurgery 1981; 54: 406-408.

25. Waga, S., Shimizu, T., Shimosaka, S., Tochio, H.: Intratumoral hemorrhage after a ventriculoperitoneal shunting procedure. Neurosurgery 1981; 9: 249-252. 
26. Waga, S., Shimosaka, S., Sakakura, M.: Intracerebral hemorrhage remote from the site of the initial neurosurgical procedure. Neurosurgery 1983; 13: 662-665.

27. Zuccarello, M., Dollo, C., Carollo, C.: Spontaneous intratumoral hemorrhage after ventriculoperitoneal shunting. Neurosurgery 1985; 16: 245-246.
Alcázar, L.; Alfaro, R.; Tamarit, M.; Gómez-Angulo, J.C.; . Ortega, J.M.; Aragonés, P.; Jerez, P.; Salazar, F.; del Pozo, J.M.: Delayed intracerebral hemorrhage after ventriculoperitoneal shunt insertion. Case report and literature review. Neurocirugía 2007; 18: 128-133.

Corresponding author: Lucía Alcázar Vaquerizo. Department of Neurosurgery. The Getafe Universitary Hospital. Toledo Road, Km. 12.500. 28905 Getafe. Madrid. Spain. 